\title{
An ALK-positive lung adenocarcinoma with gastric and skin metastasis: a case report and literature review
}

\author{
Xueqin Duan, Xinhan Zhao, Shuhong Wang \\ Department of Oncology, The First Affiliated Hospital of Xi'an Jiao Tong University, Xi'an, China \\ Correspondence to: Shuhong Wang. Department of Oncology, The First Affiliated Hospital of Xi'an Jiao Tong University, No. 277 Yanta West Road, \\ Yanta District, Xi'an 710000, China. Email: wsh2003@126.com.
}

\begin{abstract}
Primary lung cancer with gastric metastasis is rare to see in the world, little is known about its characteristics. Here, we describe the first case of primary lung adenocarcinoma with gastric and skin metastases along with a review of literature to help clinical decision making. A 49-year-old woman admitted to our department for abdominal distension. The immunohistochemistry staining for the biopsy in the gastric fundus, back and lung showed positive for CK5/6, TTF-1, Napsin A and CK7, but negative for CK20, which strongly indicated all of them were homologous and might originate from lung adenocarcinoma. Chromosome mutation analysis presented an EML4-ALK fusion gene. Brain metastases occurred after 6 months with crizotinib treatment. More than two months later, intracranial lesions became more and larger as she persisted in taking crizotinib plus whole-brain radiotherapy (WBRT). Hence, alectinib was performed due to the continuous growth of brain lesions. When reexamined three months later, the craniocerebral lesions were significantly reduced and all tumor markers were up to normal level. This review comprised 42 published case reports in total. Generally, the average morbidity age was 62 years old, and male with smoking history were more prone to it. It could be found that squamous cell carcinoma (17/38) accounts for a high proportion of gastrointestinal metastases pathology, most of which were poorly differentiated. Surgical excision of the lesions was supposed to improve long-term prognosis, mitigate associated complications, decrease patients' pain, and enhance the quality of life. Gastric metastasis of lung cancer is apt to metastasize to the brain, and the prognosis is inferior. Crizotinib with preventive WBRT may be the optimal choice for NSCLC patients harboring ALK mutation in the initial treatment of gastric metastasis. However, If the lesion in the brain keep on going, timely replacement to alectinib is an appropriate choice.
\end{abstract}

Keywords: Lung cancer; gastric metastasis; ALK-positive; case report

Submitted Apr 26, 2020. Accepted for publication Jul 21, 2020.

doi: 10.21037/apm-20-1025

View this article at: http://dx.doi.org/10.21037/apm-20-1025

\section{Introduction}

For both sexes combined, lung cancer is the most commonly diagnosed cancer and time leading cause of cancer death (1). Half of patients have metastatic diseases at the time of diagnosis, with survival rates of $20 \%$ at 1 year and $1 \%$ at 5 years (2). The most common site of extra pulmonary spread included liver (35\%), bones (25\%), adrenals (22\%), kidneys (10-15\%) and heart pericardium (20\%) (3). Gastric metastasis of lung cancer is rare in clinic, and there are few reports in literature. The actual incidence of gastric metastasis from lung cancer is hard to calculate as patients suffered it are asymptomatic which are easily to be ignored. It seems to be some controversy in the diagnosis of gastric metastasis from lung cancer, let alone have some recommendations for treatment and established prognosis.

In this paper, we report a case of lung adenocarcinoma with EML4-ALK-positive that metastasized to gastric and skin, and systematically review previous case reports for better understanding of its clinicopathological features, 


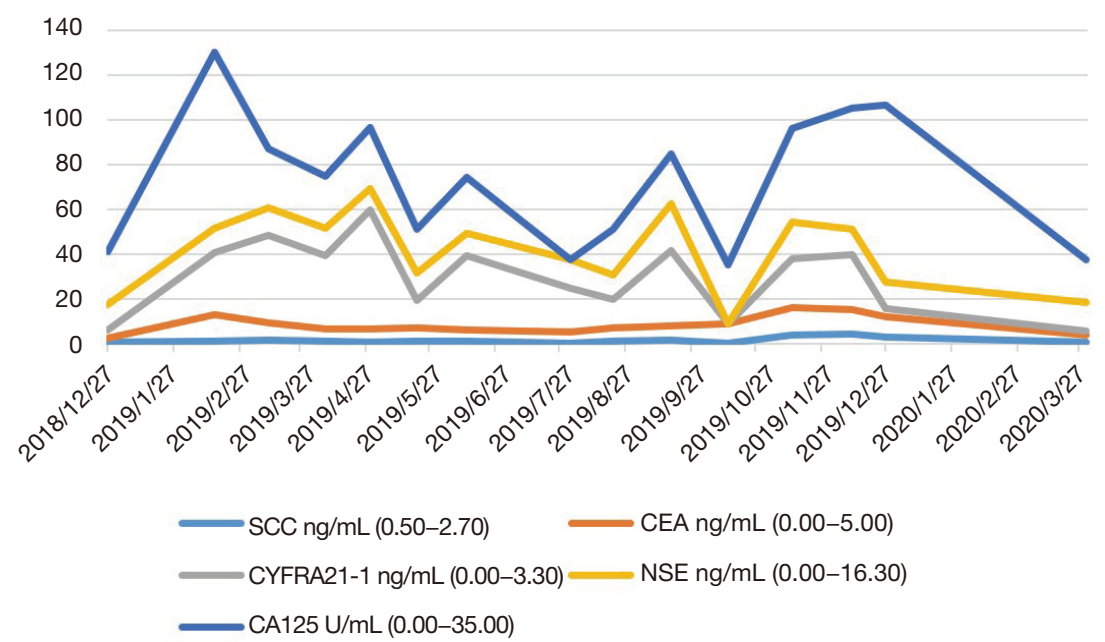

Figure 1 Changes in tumor markers during treatment. It seems that all tumor markers would change more or less over the duration of treatment. Among them, the values SCC and NSE were within standard ranges. A majority of CEA values were mostly higher than the normal. Cyfra21-1 values were all above the normal range, with a significant upward trend in January, April, June, September. CA-125 values were mostly below the normal, however, it increased significantly in January and November. SCC, squamous cell carcinoma; NSE, neuronspecific enolase; CEA, Carcinoembryonic antigen.

prognosis and optimal treatment strategy.

We present the following case in accordance with the CARE reporting checklist (available at http://dx.doi. org/10.21037/apm-20-1025).

\section{Case presentation}

The patient, a 41-year-old female, was admitted to our department on December 27, 2018 with chief complain of abdominal distension for 2 months. She was neither a smoker nor a drinker. She has not seen at any other hospital before. There was no cancer history or any other certain diseases history in her family. A tough lump on the back with $9.2 \mathrm{~cm} \times 5.6 \mathrm{~cm}$ in size was detected during the physical examination. The lump underneath the skin was moveable, painless and the shape was regular.

Laboratory examinations were as follows: Cytokeratin 19 fragment (CYFRA21-1): $3.98 \mathrm{ng} / \mathrm{mL}$ (normal range, 0.00-3.30 ng/mL); Carbohydrate antigen199 (CA199): $143.20 \mathrm{U} / \mathrm{mL}$ (normal range, 0.00-39.00 U/mL); Carbohydrate antigen-125 (CA-125): $23.8 \mathrm{U} / \mathrm{mL}$ (normal range, $0.00-35.00 \mathrm{U} / \mathrm{mL}$ ); Carcinoembryonic antigen (CEA): $1.70 \mathrm{ng} / \mathrm{mL}$ (normal range, $0.00-3.40 \mathrm{ng} / \mathrm{mL}$ ) (Figure 1). The patient underwent ultrasound-guided percutaneous biopsy of the skin to obtain the histological examination specimen, which indicated a poorly differentiated adenocarcinoma. Immunohistochemical staining showed positive expression in cytokeratin 5/6 (CK5/6), thyroid transcription factor-1 (TTF-1) and cytokeratin 7 (CK7), but negative expression in Napsin $\mathrm{A}(-)$, and cytokeratin 20 (CK20). Gastroscopy revealed two protruding lesions in the gastric fundus whose biopsy indicating a poorly differentiated metastatic adenocarcinoma (Figure 2). We have a consultation with the pathologist to make a definite diagnosis. The pathology department thought that there was a high homology between the gastric fundus and dorsal biopsy, both of which may originate from lung adenocarcinoma. Chest computed tomography was performed, which revealed a mass measuring $4 \mathrm{~cm}$ next to the right lung hilum (Figure 3). A CT-guided percutaneous transthoracic needle aspiration biopsy of the mass was carried out, revealing a poorly differentiated adenocarcinoma. Immunohistochemical stained CK5/6, TTF-1, Napsin A and CK7 positive, while stained CK20 negative, which confirming the diagnosis of gastric metastasis from lung adenocarcinoma. The patient had an echinoderm microtubule-associated protein-like 4 (EML4)-ALK fusion gene.

Therefore, oral treatment with crizotinib $(250 \mathrm{mg}$, twice a day) started on January 20, 2019. Diarrhea and mild increase in liver enzymes occurred during targeted therapy, but became resistant after symptomatic support therapy. 


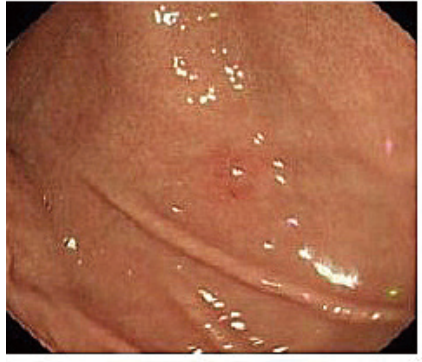

Gastric fundus fornix

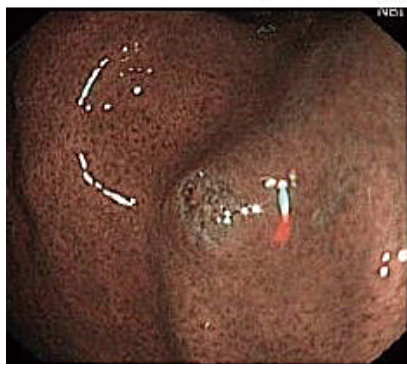

Gastric fundus anterior wall

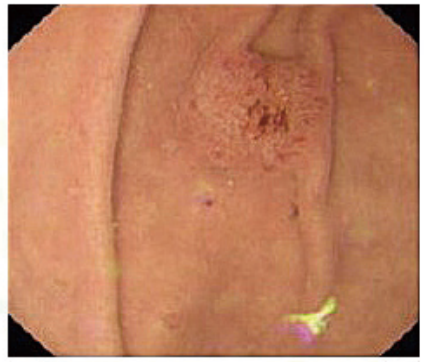

Greater curvature of fundus

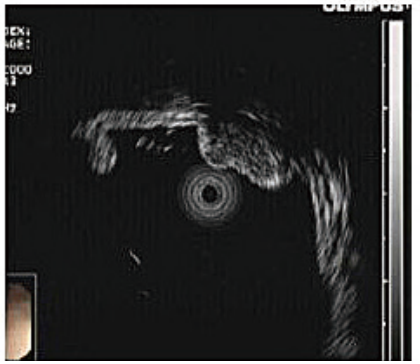

Greater curvature of fundus

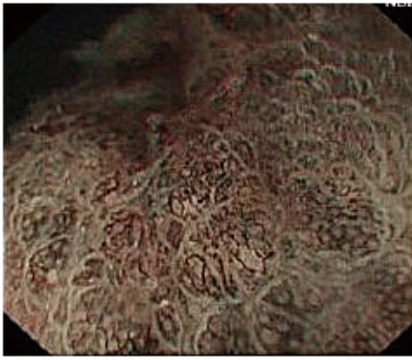

Greater curvature of fundus

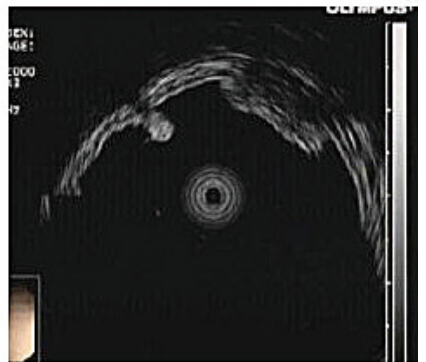

Greater curvature of fundus

Figure 2 Gastroscopy revealed two protruding lesions in the fundus. One in the greater curvature measuring $1.0 \mathrm{~cm} \times 1.0 \mathrm{~cm}$ with mucosa erosion and hyperemia and the other in the fundus fornix of stomach with $0.3 \mathrm{~cm} \times 0.4 \mathrm{~cm}$ in size.

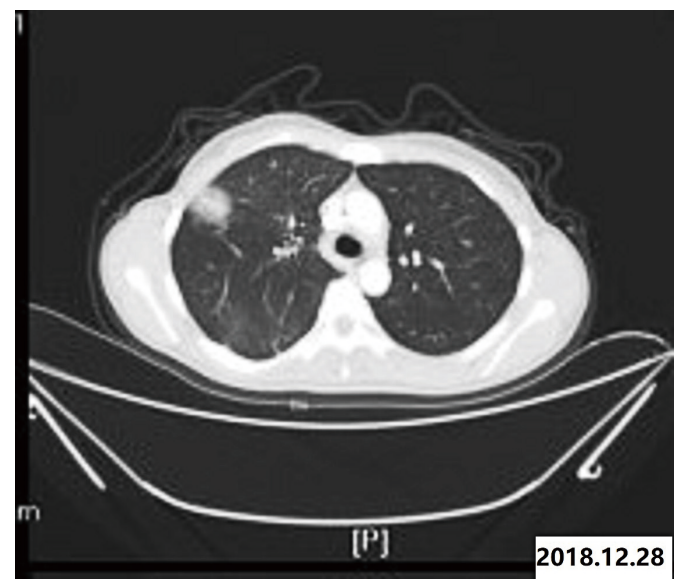

Figure 3 Enhanced CT scan of the chest. It demonstrates a solitary round mass next to the right lung hilum measuring $3.8 \mathrm{~cm} \times 4.0 \mathrm{~cm}$ with a blurry margin, spiculation sign.

Two months later, comparing with the former image of chest CT, the mass size in the right lung hilum was slightly smaller than before. The lesions were considered to be stable, which proved that molecular targeted therapies could be effective in this disease. The chest CT on July 1, 2019 (compared with on February 18, 2019) showed a reduction

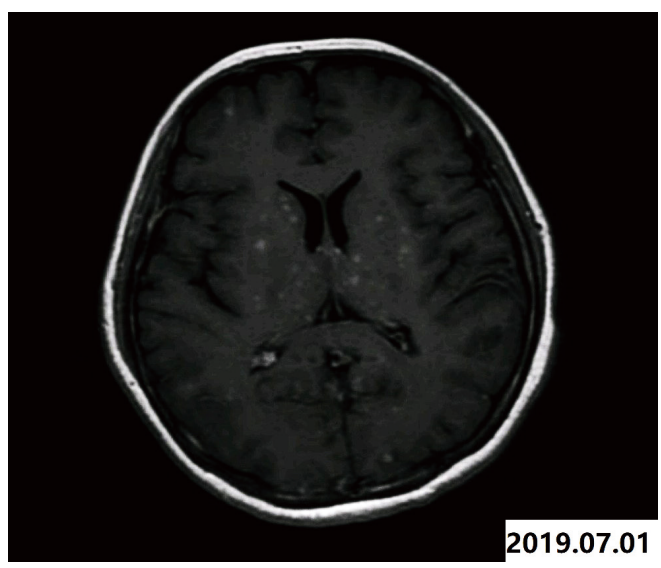

Figure 4 Magnetic imaging of the brain. It revealed multiple spotted abnormal signal shadows in the cerebellum and brainstem.

in the volume of the mass in the right hilum of the lung. Almost at the same time, multiple nodules in the brain were found by magnetic resonance imaging (MRI), which was considered to be the occurrence of brain metastasis (Figure 4). The patient's primary lesion was reduced and intracranial metastasis was observed. According to RECIST 1.1 criteria (4), it can be identified as progressive disease 


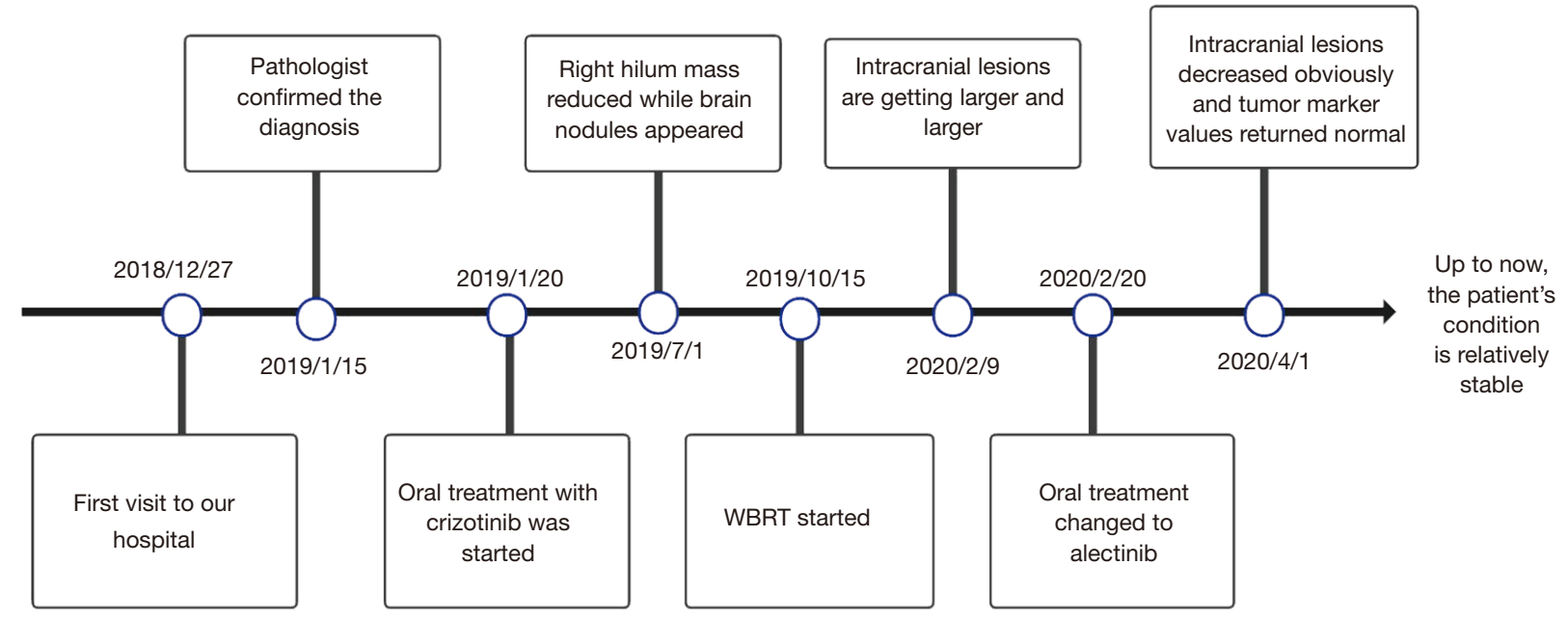

Figure 5 Timeline. It demonstrates the diagnosis, treatment and prognosis of our case report succinctly. WBRT, whole-brain radiotherapy.

(PD). It was difficult to determine whether to continue local radiotherapy with crizotinib or to change to alectinib directly. Global brain radiation therapy (WBRT) started on October 15, 2019 (30 Gy/10 times) due to the patient's refusal to use alectinib for personal reasons. After 7 months, there was no significant change in primary lung lesions. Whereas, the intracranial lesions on the enhanced brain MRI images are getting larger and larger compared with that on July 9, 2019. Finally, the patient agreed to take alectinib (600 $\mathrm{mg}$, twice a day) as a follow-up treatment. On April 1, 2020, intracranial lesions decreased obviously and all tumor marker values returned to the normal range. Up to now, the patient's condition is relatively stable. For a better idea of this case, a timeline figure is established (Figure 5). All procedures performed in studies involving human participants were in accordance with the ethical standards of the institutional and/or national research committee(s) and with the Helsinki Declaration (as revised in 2013). All treatments were performed with the consent of the patient. Written informed consent was obtained from the patient for publication of this study and any accompanying images.

Systematic review. After searching for all possible eligible case reports and their references in PubMed and CNKI (China National Knowledge Infrastructure), combined with our case, a systematic review was conducted. Table 1 summarized the patients' clinical characteristics, and Table 2 showed the tumors' pathology, treatment and prognosis. We collected 42 patients with an average age of 62 years (ranged, 39-90 years), comprised of 35 males $(83.3 \%)$ and 7 females (16.7\%). Twenty-five of these cases have a definite smoking history and six cases with no smoking history. Although the location of lung cancer is varied, the upper lobe has a predominance to be involved. Squamous cell carcinoma (17/38) attribute to the main pathology type, followed by adenocarcinoma (15/42), small cell lung cancer (5/38), large cell carcinoma $(3 / 38)$ and polymorphic cell carcinoma (2/38). Most of them are undifferentiated or poorly differentiated. The initial symptom that metastasized to the gastrointestinal tract in the review mostly was epigastric pain. Signs of gastrointestinal bleeding including hematemesis, melena, and chronic anemia. Different cancer treatment strategies would lead to a completely distinct response and prognosis. The interval for the diagnosis of gastric metastasis subsequent to the primary tumor ranged from 0 to 36 months with 3.9 months in average. Twentythee patients had lung cancer and gastric cancer at the same time, which were later confirmed to be lungcancer related by immunohistochemistry. There are $60 \%(25 / 42)$ of patients accompanied by other clinically detectable metastatic lesions like liver, bone, brain and skin at the diagnosis of the gastric metastases. Ten patients underwent palliative treatment after gastric metastasis and 12 underwent an operation to improve their survival. On account of final results and follow-up time were not mentioned in $33.3 \%$ of previous cases, the overall survival, 1 -year post-metastasis survival rate as long as 5 -year postmetastasis survival rate could not be calculated correctly. 
Table 1 Clinical features of patients with gastric metastasis from lung cancer in the literature

\begin{tabular}{|c|c|c|c|c|c|c|c|c|}
\hline Author & Case & Age (y/o) & Sex & $\begin{array}{l}\text { Smoking } \\
\text { history }\end{array}$ & $\begin{array}{c}\text { Clinical presentation of } \\
\text { gastric cancer }\end{array}$ & $\begin{array}{c}\text { Primary lung } \\
\text { location }\end{array}$ & $\begin{array}{l}\text { Gastric } \\
\text { location }\end{array}$ & $\begin{array}{l}\text { Other metastatic } \\
\text { sites }\end{array}$ \\
\hline Fushi Wei (5) & 1 & 60 & $\mathrm{M}$ & NM & Abdominal distension & NM & Fundus & Liver \\
\hline Yuyan Wang (7) & 3 & 71 & $\mathrm{M}$ & Y & $\begin{array}{l}\text { Fecal occult blood } \\
\text { positive }\end{array}$ & LRL & Fundus & None \\
\hline Hs Kim (9) & 5 & 68 & $\mathrm{M}$ & Y & NM & ULL & Body & Brain \\
\hline Song Gao (10) & 6 & 66 & $\mathrm{M}$ & NM & NM & $\mathrm{RH}$ & Body & Liver \\
\hline Qingyuan Huang (11) & 7 & 61 & $\mathrm{~F}$ & $\mathrm{~N}$ & Epigastric discomfort & LRL & Cardia & None \\
\hline Min Hee Lee (12) & 8 & 77 & $\mathrm{M}$ & NM & Abdominal pain & URL & Antrum & NM \\
\hline Keiju Aokage (15) & 11 & 69 & $\mathrm{M}$ & NM & Anemia & URL & Body & None \\
\hline Keiju Aokage (15) & 12 & 62 & $M$ & NM & NM & ULL & Body & None \\
\hline Ciğdem Ozdilekcan (3) & 13 & 43 & $\mathrm{M}$ & $\mathrm{Y}$ & Abdominal distension & URL & Body & None \\
\hline Engin Altintas (16) & 14 & 55 & $\mathrm{M}$ & NM & Melena & NM & Body & Brain, bone, skin \\
\hline Ibrahim Azar (17) & 15 & 90 & $\mathrm{M}$ & NM & Melena & ULL & Body & Liver \\
\hline Our case & 16 & 41 & $\mathrm{~F}$ & $\mathrm{~N}$ & Abdominal distension & $\mathrm{RH}$ & Fundus & Skin, brain \\
\hline Hs Kim (9) & 17 & 66 & $\mathrm{M}$ & $\mathrm{Y}$ & Abdominal pain & ULL & Body, Fundus & Bone \\
\hline Motoharu Hamatake (20) & 21 & 65 & $\mathrm{M}$ & Y & Acute hematemesis & LLL & Body & NM \\
\hline Miyazaki J (21) & 22 & 54 & $\mathrm{M}$ & $\mathrm{Y}$ & $\begin{array}{l}\text { Abdominal pain, } \\
\text { anemia }\end{array}$ & URL & Antrum & Cecum, liver \\
\hline Alpar S (22) & 23 & 66 & M & Y & NM & NM & NM & NM \\
\hline Ying $\mathrm{He}(23)$ & 24 & 61 & $\mathrm{M}$ & Y & Dysphagia & LLL & Fundus & None \\
\hline Stamatis Katsenos (24) & 25 & 61 & $\mathrm{M}$ & $\mathrm{Y}$ & Melena & ULL & Body & Liver, bone, brain \\
\hline Takayuki Jujo (25) & 26 & 73 & M & NM & None & URL & Body & Liver, bone \\
\hline Ihab I. El Hajj (26) & 27 & 59 & M & NM & $\begin{array}{l}\text { Nausea, abdominal } \\
\text { pain }\end{array}$ & URL & Fundus & $\begin{array}{c}\text { Pancreas, splenic } \\
\text { vein }\end{array}$ \\
\hline Mohammad Esmadi (27) & 28 & 62 & $\mathrm{~F}$ & Y & $\begin{array}{l}\text { Abdominal pain, } \\
\text { melena }\end{array}$ & $\mathrm{LH}$ & NM & $\begin{array}{l}\text { Adrenal glands, } \\
\text { bone, soft tissue }\end{array}$ \\
\hline Ayman Qasrawi (28) & 29 & 69 & $\mathrm{~F}$ & $\mathrm{~N}$ & Melena & ULL & Body & Brain \\
\hline Tsung I Hung (29) & 30 & 47 & M & Y & None & URL & Body & Left adrenal gland, \\
\hline
\end{tabular}

Table 1 (continued) 
Table 1 (continued)

\begin{tabular}{|c|c|c|c|c|c|c|c|c|}
\hline Author & Case & Age $(y / o)$ & Sex & $\begin{array}{l}\text { Smoking } \\
\text { history }\end{array}$ & $\begin{array}{c}\text { Clinical presentation of } \\
\text { gastric cancer }\end{array}$ & $\begin{array}{l}\text { Primary lung } \\
\text { location }\end{array}$ & $\begin{array}{l}\text { Gastric } \\
\text { location }\end{array}$ & $\begin{array}{c}\text { Other metastatic } \\
\text { sites }\end{array}$ \\
\hline Mariko Nemoto (30) & 31 & 64 & M & $\mathrm{Y}$ & $\begin{array}{l}\text { Epigastric pain and } \\
\text { progressive dysphagia }\end{array}$ & LRL & Cardia & Liver \\
\hline Xinyu Li (31) & 32 & 61 & M & $\mathrm{N}$ & Abdominal distention & LRL & Body & None \\
\hline Richa Bhardwaj (32) & 33 & 39 & $\mathrm{~F}$ & $\mathrm{Y}$ & $\begin{array}{l}\text { Dizziness and black } \\
\text { tarry stools }\end{array}$ & LRL & Fundus & $\begin{array}{c}\text { Bone and lymph } \\
\text { nodes }\end{array}$ \\
\hline Punit Sharma (33) & 34 & 59 & M & $\mathrm{N}$ & None & URL & Body & None \\
\hline Charlotte Bouzbib (34) & 35 & 64 & M & Y & Acute anemia & LLL & Fundus & None \\
\hline Jian-Bin Hu (35) & 36 & 54 & M & $\mathrm{Y}$ & Dysphagia & $\mathrm{RH}$ & Body & Lymph node \\
\hline Stamatis Katsenos (24) & 37 & 61 & M & Y & Melena & ULL & Body & Brain, bone \\
\hline E. Guérin (37) & 40 & 72 & M & NM & $\begin{array}{l}\text { Epigastric, pain, } \\
\text { heartburn }\end{array}$ & $\mathrm{LH}$ & NM & $\begin{array}{l}\text { Adrenal gland, } \\
\text { slenic hilum, skin }\end{array}$ \\
\hline Cornelia Nitipir (38) & 41 & 66 & M & $\mathrm{Y}$ & Abdominal pain & Left lobe & Fundus & $\begin{array}{l}\text { Liver, kidneys, } \\
\text { bones, brain }\end{array}$ \\
\hline Naoki Hasegawa (39) & 42 & 74 & $M$ & $Y$ & None & URL & Body & None \\
\hline
\end{tabular}

M, male; F, female; Y, yes; N, no; NM, not mentioned; ULL, upper left lobe; URL, upper right lobe; LRL, lower right lobe; LLL, lower left lobe; $\mathrm{RH}$, right hilum; $\mathrm{LH}$, left hilum.

\section{Discussion}

The incidence of gastric metastasis from lung carcinoma has been reported to range from $0.19-5.1 \%$ [4] (19). While the rate of gastric metastasis incidence was significantly higher in the autopsy reaching $2-14 \%(17,40)$. Under this circumstance, we can reasonably speculate that the occurrence of gastrointestinal metastases may represent a poor prognosis. Lung cancer with gastric metastasis is more likely to occur in the old, and male patients are more susceptible. Whether stomach ailments history worked in the tumor progress or not was unclear, as little previous cases contain the history of gastropathy.

In review of previous cases, the most common histopathological type of metastasis to the gastrointestinal tract was underdetermined as previous studies about it varied in their findings. Our study showed that squamous cell carcinoma was prone to cause gastric metastasis, which is consistent with previous studies (41). However, there were still other certain studies and autopsy series had shown adenocarcinoma to be prominent (31). At present, the cause of gastric metastasis is not clear. It is suspected that some cytokines may affect the organ specificity of blood metastasis (40). Metastatic gastric cancer generally occurred in the gastric body, while the vast majority of primary gastric cancer present in the gastric antrum (5). However, it is still visible in the gastric body and gastric fundus. Therefore, immunohistochemistry is a reliable method to distinguish primary from metastatic gastric cancer. The commonly used markers for subtyping non-small cell lung cancer included TTF-1, CK7, Napsin A for adenocarcinoma, and p63, CK5/6, CK34ßE12/CK903 for SCC (38). TTF1 is highly specific for adenocarcinomas of pulmonary origin exhibiting a positive predictive value of $100 \%$ $(2,13)$. Also, primary lung carcinomas usually express the immunophenotype of CK7+/CK20-, while gastrointestinal carcinomas have the CK7-/CK20+ pattern (2). Since CK7+/CK20- immunophenotype still could be observed in $45 \%$ of patients with gastrointestinal cancers such as primary rectal or small bowel adenocarcinomas, using TTF-1 in combination with CK7 and CK20 could differentiate primary gastric tumor from metastatic gastric tumor with reasonable degree of certainty (24). Gastric 
Table 2 Pathological features, treatment and prognosis of secondary gastric cancer

\begin{tabular}{|c|c|c|c|c|c|c|c|c|}
\hline Case & $\begin{array}{l}\text { Cancer cell } \\
\text { type }\end{array}$ & Histology & $\begin{array}{l}\text { Time span } \\
\text { (months) }\end{array}$ & $\begin{array}{l}\text { Time interval } \\
\text { (months) }\end{array}$ & \multicolumn{2}{|c|}{ Treatment protocols } & Outcome & $\begin{array}{l}\text { Overall } \\
\text { surviva }\end{array}$ \\
\hline 1 & $A C$ & NM & 36 & NM & $\begin{array}{l}\text { Lung cancer } \\
\text { resection }\end{array}$ & $\begin{array}{c}\text { Radical gastrectomy and } \\
\text { chemotherapy }\end{array}$ & Alive & $>39$ \\
\hline 2 & SCC & PD & $<12$ & 4 & $\begin{array}{l}\text { Pulmonary } \\
\text { lobectomy }\end{array}$ & Supporting therapy & Died & 16 \\
\hline 4 & SCLC & UN & NM & NM & Chemotherapy & Chemotherapy & Died & 12 \\
\hline 5 & SCC & PD & 0 & NM & NM & NM & NM & NM \\
\hline 6 & SCLC & UN & 14 & 3 & Chemotherapy & Chemotherapy & Died & 17 \\
\hline 8 & $A C$ & PD & 0 & NM & $\begin{array}{l}\text { Right upper } \\
\text { lobectomy }\end{array}$ & Subtotal gastrectomy & NM & NM \\
\hline 9 & $A C$ & PD & 0 & 12 & $\begin{array}{l}\text { Right lower } \\
\text { lobectomy }\end{array}$ & Chemotherapy & Died & 12 \\
\hline 10 & SCLC & PD & 0 & 1 & Supportive care & Supportive care & Died & 1 \\
\hline 11 & PC & NM & $>5$ & NM & Lung lobectomy & Distal gastrectomy & Alive & $>60$ \\
\hline 12 & $\mathrm{PC}$ & NM & 0 & NM & $\begin{array}{l}\text { Left upper } \\
\text { lobectomy and } \\
\text { lymph node } \\
\text { dissection }\end{array}$ & Partial gastrectomy & Alive & $>48$ \\
\hline 16 & $A C$ & PD & 0 & NM & Targeted therapy & Targeted therapy & Alive & $>15$ \\
\hline 17 & SCLC & UN & 0 & NM & NM & NM & NM & NM \\
\hline 18 & $A C$ & NM & 0 & 15 & Chemotherapy & Chemotherapy & Died & 15 \\
\hline 19 & $A C$ & PD & 0 & NM & Targeted therapy & Targeted therapy & NM & NM \\
\hline 20 & $A C$ & NM & 0 & 11 & None & Total gastrectomy & Died & $>12$ \\
\hline 21 & SCC & PD & 0 & 5 & $\begin{array}{l}\text { Left lower } \\
\text { lobectomy } \\
\text { with a partial } \\
\text { resection of the } \\
\text { lingual segment } \\
\text { and combined } \\
\text { resection of the } \\
\text { chest wall }\end{array}$ & Total gastrectomy & Died & 5 \\
\hline
\end{tabular}

Table 2 (continued) 
Table 2 (continued)

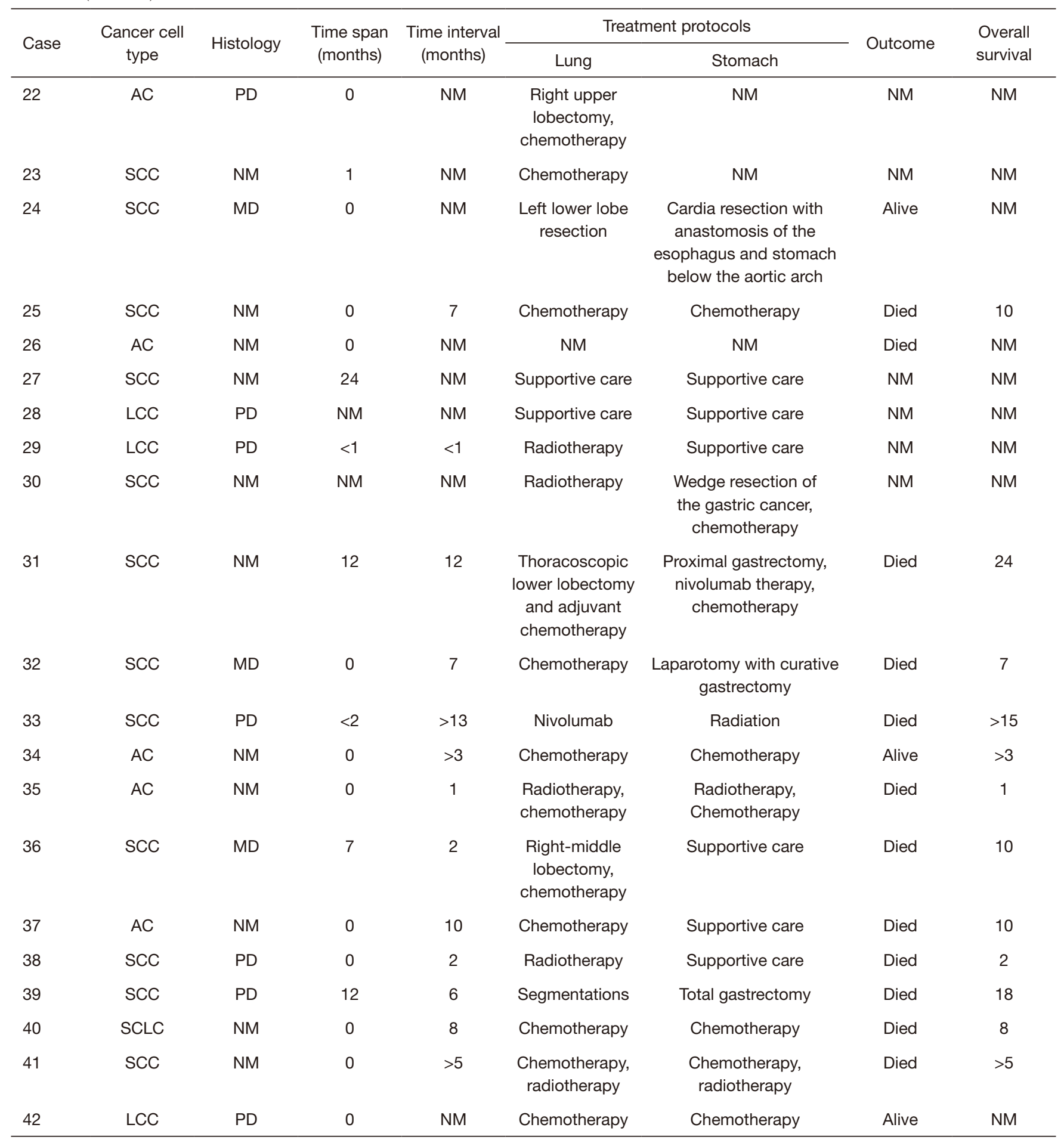

Time span: time interval between diagnosis of primary lung cancer and gastric metastasis (months); time interval: the time from the discovery of gastric metastases to the death; SCC, squamous cell carcinoma; AC, adenocarcinoma; SCLC, small cell lung cancer; PC, pleomorphic carcinoma; LCC, large cell carcinoma; UN, undifferentiated; PD, poorly differentiated; MD, moderately differentiated; NM, not mentioned. 
metastases initially occurred in the submucosal layer and only when the metastatic lesions grow and cause obstruction or ulceration could patients develop symptoms (13). The clinical manifestations of gastric metastatic carcinoma are not peculiar. Most of the complaints were epigastric pain or distension, which was easy to be ignored. Consequently, little could be seen of it in clinic. For patients with a history of the primary tumor, gastrointestinal reactions should not only be considered as adverse reactions caused by chemotherapy, but also the possibility of metastasis. Timely endoscopic examination should be made to clarify the pathology. The use of ${ }^{18} \mathrm{~F}$-fluorodeoxyglucose positron emission tomography (FDG-PET) was very useful to detect gastrointestinal metastasis of lung cancer, as it could identify occult metastases of primary cancer prior to several diagnostic methods including gastroduodenoscopy, colonoscopy, abdominal CT and small bowel series (42).

At present, there is no unified treatment plan for patients with gastric metastasis of lung cancer and optimal treatment would be made according to pathology and patients' condition. Due to the dismal outcomes, a summary of previous case reports shows that $24 \%$ of the patients have chosen palliative care treatment. In the management of gastric metastasis, instead of chemotherapy or just supporting alone, combined with palliative operation may lead to a more favorable outcome. For instance, two patients with gastric metastasis of lung cancer who underwent subtotal gastrectomy had a long-term survival time of more than 4 years (15). Aokage et al. (15) thought pathologic stage I patients with a solitary recurrence after complete non-small cell lung cancer resection can prolong the survival time, while it doesn't suit for the stage II/III patient. However, since digestive tract tumors are prone to perforation, obstruction and bleeding, early and less invasive intervention such as palliative resection or bypass surgery may be needed to prevent or control severe complications (15).

Our patient had an EML4-ALK-positive gene. ALK gene rearrangements are detected in 3-7\% of NSCLC patients (43). Compared with chemotherapy, ALK inhibitors significantly prolonged progression-free survival and overall survival in patients with ALK-positive in advanced NSCLC (44). After 6 months of treatment with crizotinib, there is a progression of the disease. Our patients had a shorter progression-free survival, in sharp contrast to 11.5 months mentioned in clinical study PROFILE 1014 about the efficacy of crizotinib treatment (44). CNS was a frequent site of acquiring resistance to crizotinib. It was reasonable to suppose that ALK-positive lung cancer with gastric metastasis was more likely to occur brain metastases and was worse prognosis than others organ metastasis. For them, crizotinib combined with local treatment might be related to the clinical efficacy and would prolong the progression free survival in the initial treatment. Retrospective data showed that alectinib treatment after crizotinib failure can improve sustained control and overall survival in patients with ALK rearrangement of NSCLC (45). After brain metastasis, the replacement of alectinib in time, rather than the persistence of combination of crizotinib and local radiotherapy, may achieve more encouraging results. However, we switched crizotinib to alectinib only when the brain lesions had progressed.

This study systematically summarized the clinical characteristics, treatment and prognosis of gastric metastasis of lung cancer, in order to provide a better reference for clinical decision-making. We also proposed a feasible therapy for EML4-ALK-positive lung cancer, and summarized some experience. The limitation of the study is that the feature data we summarized may not fully represent the real feature data due to the selection bias. The cases included in our study only come from the literature available in PubMed. There still are many suitable cases that haven't been reported or even be misdiagnosed fail to be enrolled.

In conclusion, though less occurrence of lung cancer with gastric metastasis, attention should be paid when gastrointestinal symptoms occurred for patients with lung cancer. Timely detection of gastric metastases and initiation of appropriate treatment could improve the quality of life and prolong survival. There was no clinical study on whether to continue using crizotinib combined with local radiotherapy, or to use alectinib when brain metastasis occurs. In comparison with other site metastasis, the occurrence of gastric metastases of ALK-positive lung cancer was seemed to accelerate the process of brain metastasis. Hence, it could be speculated that the combination use of crizotinib and prophylactic whole brain radiotherapy simultaneously was the optimal treatment at the beginning of the intervention. In our cases, timely replacement was appropriate when intracranial lesions were gradually increased.

\section{Acknowledgments}

Funding: None. 


\section{Footnote}

Reporting Checklist: The authors have completed the CARE reporting checklist. Available at http://dx.doi.org/10.21037/ apm-20-1025

Conflicts of Interest: All authors have completed the ICMJE uniform disclosure form (available at http://dx.doi. org/10.21037/apm-20-1025). The authors have no conflicts of interest to declare.

Ethical Statement: The authors are accountable for all aspects of the work in ensuring that questions related to the accuracy or integrity of any part of the work are appropriately investigated and resolved. All procedures performed in studies involving human participants were in accordance with the ethical standards of the institutional and/or national research committee(s) and with the Helsinki Declaration (as revised in 2013). All treatments were performed with the consent of the patient. Written informed consent was obtained from the patient for publication of this study and any accompanying images.

Open Access Statement: This is an Open Access article distributed in accordance with the Creative Commons Attribution-NonCommercial-NoDerivs 4.0 International License (CC BY-NC-ND 4.0), which permits the noncommercial replication and distribution of the article with the strict proviso that no changes or edits are made and the original work is properly cited (including links to both the formal publication through the relevant DOI and the license). See: https://creativecommons.org/licenses/by-nc-nd/4.0/.

\section{References}

1. Bray F, Ferlay J, Soerjomataram I, et al. Global cancer statistics 2018: GLOBOCAN estimates of incidence and mortality worldwide for 36 cancers in 185 countries. CA Cancer J Clin 2018;68:394-424.

2. Michael DR, Henry T. Not all gastric masses are gastric cancer. BMJ Case Rep 2016;2016:bcr2015213535.

3. Ozdilekcan C, Songür N, Memiş L, et al. Lung cancer associated with a single simultaneous solitary metastatic lesion in stomach: a case report with the review of literature. Tuberk Toraks 2010;58:78-84.

4. Eisenhauer EA, Therasse P, Bogaerts J, et al. New response evaluation criteria in solid tumours: revised RECIST guideline (version 1.1). Eur J Cancer 2009;45:228-47.
5. Fu SW, Yang YH, Huang X, et al. Clinicopathologic characteristics of gastric metastasis from primary lung cancer: a case report and review of the literature. World Chinese Journal of Digestology 2014;22:2657-60.

6. Wang ZY, Mu ZB, Zhang Y. Clinical features of primary lung cancer metastases to the stomach one case report and literature. Chin J Clinicians 2016;10:223-4.

7. Wang Y, An TT, Yang L, et al. Primary lung cancer with gastrointestinal metastasis: 2 case report and literature review. Zhongguo Fei Ai Za Zhi 2011;14:278-80.

8. Liu YP, Jin B, Wang QS. Metastatic carcinoma to the stomach from different primary sites: An analysis of 12 cases. World Chinese Journal of Digestology 2012;20:2092-6.

9. Kim HS, Jang WL, Hong HS, et al. Metastatic involvement of the stomach secondary to lung carcinoma. J Korean Med Sci 1993;8:24-9.

10. Gao S, Hu XD, Wang SZ, et al. Gastric metastasis from small cell lung cancer: a case report. World J Gastroenterol 2015;21:1684-8.

11. Huang Q, Su XD, Bella AE, et al. Clinicopathological features and outcome of gastric metastases from primary lung cancer: A case report and systematic review. Oncol Lett 2015;9:1373-9.

12. Lee MH, Kim SR, Soh JS. A solitary gastric metastasis from pulmonary adenocarcinoma: a case report. Thorax 2010;65:661-2.

13. Okazaki R, Ohtani H, Takeda K, et al. Gastric metastasis by primary lung adenocarcinoma. World J Gastrointest Oncol 2010;2:395-8.

14. Casella G, Di Bella C, Cambareri AR, et al. Gastric metastasis by lung small cell carcinoma. World J Gastroenterol 2006;12:4096-7.

15. Aokage K, Yoshida J, Ishii G, et al. Long-Term survival in two cases of resected gastric metastasis of pulmonary pleomorphic carcinoma. J Thorac Oncol 2008;3:796-9.

16. Altintas E, Sezgin O, Uyar B, et al. Acute upper gastrointestinal bleeding due to metastatic lung cancer an unusual case. Yonsei Med J 2006;47:276-7.

17. Azar I, Koutroumpakis E, Patel R, et al. Squamous cell lung carcinoma presenting as melena: a case report and review of the literature. Rare Tumors 2017;9:7164.

18. Huang YM, Hsieh TY, Chen JR. Gastric and colonic metastases from primary lung adenocarcinoma: A case report and review of the literature. Oncol Lett 2012;4:517-20.

19. Kim YI, Kang BC, Sung SH. Surgically resected gastric metastasis of pulmonary squamous cell carcinoma. World J 
Gastrointest Surg 2013;5:278-81.

20. Hamatake M, Ishida T, Yamazaki K, et al. Lung cancer with $\mathrm{p} 53$ expression and a solitary metastasis to the stomach: a case report. Ann Thorac Cardiovasc Surg 2001;7:162-5.

21. Miyazaki J, Hirota S, Abe T. Metastasis of lung cancer to the gastrointestinal tract, presenting with a volcano-like ulcerated mass. Dig Endosc 2015;27:397-8.

22. Alpar S, Kurt OK, Ucar N, et al. A case of squamous cell lung carcinoma with gastric metastasis. South Med J 2006;99:1313-4.

23. He Y, Cui Y, Duan X. Primary lung squamous cell carcinoma with gastric metastasis: A case report. Thorac Cancer 2019;10:373-7.

24. Katsenos S, Archondakis S. Solitary gastric metastasis from primary lung adenocarcinoma: a rare site of extra-thoracic metastatic disease. J Gastrointest Oncol 2013;4:E11-5.

25. Jujo T, Sakao S, Oide T, et al. Metastatic gastric cancer from squamous cell lung carcinoma. Intern Med 2012;51:1947-8

26. El Hajj II, Lawrence KA, Tirkes T, et al. Metachronous gastric metastasis from lung primary, with synchronous pancreatic neuroendocrine carcinoma. Clin Case Rep 2018;6:1368-70.

27. Esmadi M, Ahmad DS, Fu Y, et al. Upper gastrointestinal tract metastasis from lung cancer. Dig Liver Dis 2014;46:474.

28. Qasrawi A, Abu AM, Albadarin S, et al. Gastric metastases from lung adenocarcinoma causing gastrointestinal bleeding. ACG Case Rep J 2017;4:e25.

29. Hung TI, Chu KE, Chou YH, et al. Gastric Metastasis of Lung Cancer Mimicking an Adrenal Tumor. Case Rep Gastroenterol 2014;8:77-81.

30. Nemoto M, Prasoon P, Ichikawa H, et al. Primary lung squamous cell carcinoma and its association with gastric metastasis: A case report and literature review. Thorac Cancer 2020;11:1708-11.

31. Li X, Li SH, Ma ZM, et al. Multiple gastrointestinal metastases of squamous-cell lung cancer: a case report. Medicine (Baltimore) 2018;97:e11027.

32. Bhardwaj R, Bhardwaj G, Gautam A, et al. Upper gastrointestinal bleed manifestation of poorly differentiated metastatic squamous cell carcinoma of the lung. J Clin Diagn Res 2017;11:OD13-4.

33. Sharma P, Dwary AD, Khan EM, et al. Serendipitous discovery of isolated gastric metastases from adenocarcinoma of the lung on staging 18F-FDG PET-
CT. Clin Nucl Med 2017;42:807-8.

34. Bouzbib C, Chaput U, Jarrin I, et al. Bleeding from gastroduodenal metastases as the first manifestation of lung adenocarcinoma. Endoscopy 2014;46:E474-5.

35. Hu JB, Zhu YH, Jin M, et al. Gastric and duodenal squamous cell carcinoma: metastatic or primary. World J Surg Oncol 2013;11:204.

36. Tamura M, Ohta Y, Oda M, et al. Peripherally located occult lung cancer with AMFR expression. Ann Thorac Cardiovasc Surg 2003;9:184-7.

37. Guérin E, Gilbert O, Dequanter D. Acute abdomen: a rare presentation of lung cancer metastasis. Case Rep Med 2009;2009:903897.

38. Nitipir C, Ginghina O, Popa L, et al. A rare case of advanced lung cancer presenting as a symptomatic gastric tumor. Mol Clin Oncol 2018;8:595-9.

39. Naoki H, Fumihiro Y, Minoru K. Gastric metastasis of primary lung cancer. Nihon Kombu Shikkan Gakkai Zasshi 1993;31:1389-96.

40. Maeda J, Miyake M, Tokita K, et al. Small cell lung cancer with extensive cutaneous and gastric metastases. Intern Med 1992;31:1325-8.

41. Kim MS, Kook EH, Ahn SH. Gastrointestinal metastasis of lung cancer with special emphasis on a long-term survivor after operation. J Cancer Res Clin Oncol 2009;135:297-301.

42. Qasrawi A, Abu Ghanimeh M, Albadarin S, et al. Gastric metastases from lung adenocarcinoma causing gastrointestinal bleeding. ACG Case Rep J 2017;4:e25.

43. Jin Y, Chen Y, Yu X, et al. A real-world study of treatment patterns and survival outcome in advanced anaplastic lymphoma kinase-positive non-small-cell lung cancer. Oncol Lett 2018;15:8703-10.

44. Song P, Zhang L, Shang C. Current status for anaplastic lymphoma kinase in non-small cell lung cancer. Zhongguo Fei Ai Za Zhi 2018;21:703-11.

45. Del Valle MFF, Chang AY. Real world experience on treatment, outcome and toxicity of crizotinib in patients with anaplastic lymphoma kinase positive advanced nonsmall cell lung cancer. J Thorac Dis 2019;11:3864-73.

Cite this article as: Duan $\mathrm{X}$, Zhao $\mathrm{X}$, Wang S. An ALKpositive lung adenocarcinoma with gastric and skin metastasis: a case report and literature review. Ann Palliat Med 2021;10(5):57975807. doi: 10.21037/apm-20-1025 